\title{
Mechanistic Insights into the Desorption of Methanol and Dimethyl Ether Over ZSM-5 Catalysts
}

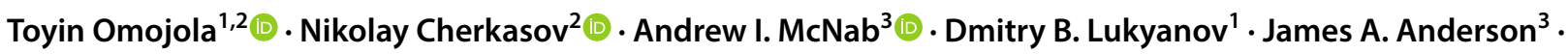 \\ Evgeny V. Rebrov ${ }^{2,4}$ (1) André C. van Veen ${ }^{2}$
}

Received: 4 September 2017 / Accepted: 13 November 2017 / Published online: 4 December 2017

(c) The Author(s) 2017. This article is an open access publication

\begin{abstract}
The desorption of methanol and dimethyl ether has been studied over fresh and hydrocarbon-occluded ZSM-5 catalysts with $\mathrm{Si} / \mathrm{Al}$ ratios of 25,36 and 135 using a temporal analysis of products reactor. The catalysts were characterized by XRD, $\mathrm{SEM}, \mathrm{N}_{2}$ physisorption and pyridine FT-IR. The crystal size increases with Si/Al ratio from 0.10 to $0.78 \mu \mathrm{m}$. The kinetic parameters were obtained using the Redhead method and a plug flow reactor model with coupled convection, adsorption and desorption steps. ZSM-5 catalysts with Si/Al ratios of 25 and 36 exhibit three adsorption sites (low, medium, and high temperature sites), while there is no difference between medium and high temperature sites at a Si/Al ratio of 135. Molecular adsorption on the low temperature site and dissociative adsorption on the medium and high temperature sites give a good match between experiment and the plug flow reactor model. The DME desorption activation energy was systematically higher than that of methanol. Adsorption stoichiometry shows that methanol and DME form clusters onto the binding sites. When non-activated re-adsorption is accounted for, a local equilibrium is reached only on the low and medium temperature binding sites. No differences were observed, other than in site densities, when extracting the kinetic parameters for fresh and activated ZSM-5 catalysts at full coverage.
\end{abstract}

\section{Graphical Abstract}

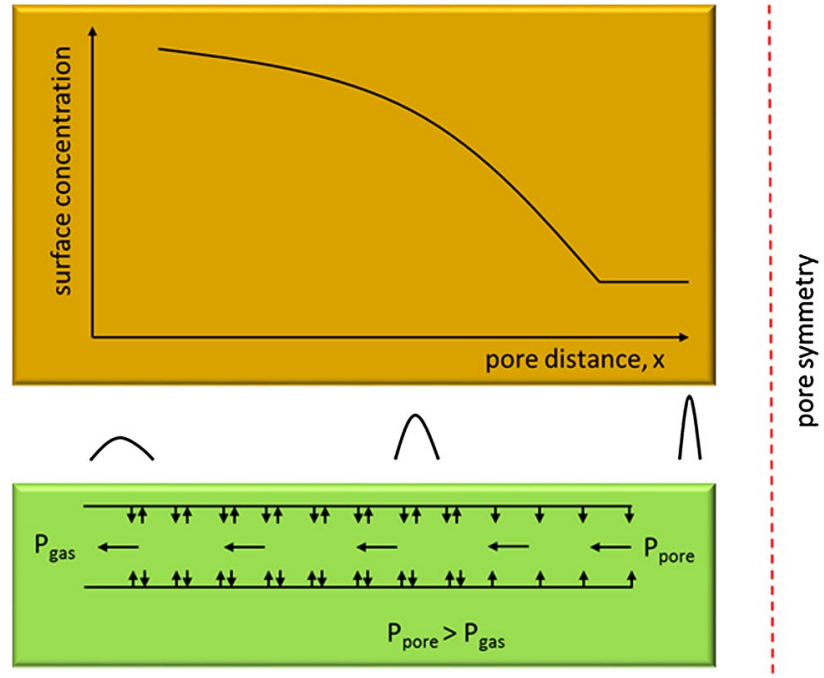

Electronic supplementary material The online version of this article (https://doi.org/10.1007/s10562-017-2249-4) contains supplementary material, which is available to authorized users.

Extended author information available on the last page of the article 
Keywords Methanol-to-hydrocarbons $\cdot$ ZSM-5 $\cdot$ TPD $\cdot$ DME $\cdot$ Methanol $\cdot$ Redhead $\cdot$ Polanyi-Wigner $\cdot$ Activation energies of desorption

\section{Introduction}

Alternative carbon sources such as biomass are vital for the secure and sustainable production of fuels and chemicals in the twenty-first century. Methanol can be produced via syngas obtained from such renewable feedstock and transformed into hydrocarbons (MTH) over zeolite catalysts [1]. ZSM-5 zeolite catalysts, typically used for MTH conversion, have a three-dimensional (3D) pore structure with 10 -membered-ring pores consisting of sinusoidal channels $(0.51 \mathrm{~nm} \times 0.55 \mathrm{~nm})$ intersecting with straight channels $(0.53 \mathrm{~nm} \times 0.56 \mathrm{~nm})$ [2]. The channel intersections have a critical diameter of $0.9 \mathrm{~nm}$ [3]. This 3D pore structure is responsible for its high selectivity and catalyst stability.

During the MTH process over ZSM-5 catalysts, methanol initially undergoes a rapid equilibration reaction leading to the formation of dimethyl ether (DME) and $\mathrm{H}_{2} \mathrm{O}$. Readily available oxygenates (methanol and DME) compete for active sites [4]. Several pieces of theoretical work [5-7] have considered the adsorption energies of initial species over ZSM-5 catalysts. Density functional theory (DFT) calculations of the adsorption of one methanol molecule onto an active site give activation energies in the range of $104-139 \mathrm{~kJ} \mathrm{~mol}^{-1}[5,8,9]$. Blaszkowski and van Santen [10-12] showed that the simultaneous adsorption and activation of two methanol molecules towards the formation of DME and $\mathrm{H}_{2} \mathrm{O}$ excluding surface methoxy group formation is the preferred pathway. However, surface methoxy groups have been readily observed with stopped flow NMR studies over ZSM-5 catalysts [13]. These surface methoxy groups can be formed by the adsorption of methanol or DME. The presence or absence of surface methoxy groups, necessary to validate the computational studies, can be linked to the dissociative or associative adsorption behaviour of oxygenates respectively.

During steady state MTH conversion, the operation of a hydrocarbon pool mechanism which regulates product distribution over zeolite catalysts is dominant $[14,15]$. Within this hydrocarbon pool framework, two catalytic cycles have been readily distinguished: an alkene cycle and an aromatic cycle. Over ZSM-5 catalysts, the transformation of methanol can be tuned towards light olefin production (MTO) at high temperatures and low pressures [16-19]. The underlying chemistry involves chain growth and cracking where larger molecules obtained through methylation by surface methoxy groups $\left(\mathrm{CH}_{3}{ }^{+} \mathrm{Z}^{-}\right)$crack to give a product distribution rich in light olefins [20]. To obtain a detailed understanding of this reaction mechanism, it is important to confirm the origin of these surface methylating species.
A current lack of knowledge on the primary surface reactant, the source of the surface methylating group, has led to the lumping of methanol and DME in previous experimental and modelling kinetic studies [20-22]. This lumping methodology is fraught in its usage as it eludes the fact that both species have different interactions with the sites of the ZSM-5 catalysts and avoids mechanistic descriptions necessary for a microkinetic model. Detailed understanding on the adsorption, desorption, and reactivity of initial oxygenates is necessary to provide site-specific comprehension of the nature and behaviour of ZSM-5 catalysts.

To verify the source of the methylating species, this paper provides a site-specific behaviour of the desorption properties of methanol and DME. Using a temporal analysis of products (TAP) reactor, temperature programmed desorption (TPD) experiments of pre-adsorbed methanol or DME were carried out over various ZSM-5 samples in a thin-zone configuration under vacuum conditions. Key parameters such as site densities, pre-exponential factors and activation energies were obtained using a detailed elementary step model i.e. a plug flow reactor model with coupled convection, adsorption and desorption steps, which was used to simulate experimental desorption profiles.

\section{Experimental Section}

All experiments were carried out with $10 \mathrm{mg}$ of ZSM-5 catalysts of different $\mathrm{Si} / \mathrm{Al}$ ratios (25, 36 and 135), here referred to as ZSM-5 (25), ZSM-5 (36) and ZSM5 (135) respectively. ZSM-5 (25) was purchased from Zeolyst International while ZSM-5 (36) and ZSM-5 (135) catalysts were obtained from BP chemicals. The ammonium form of these zeolites was pressed, crushed, and sieved to obtain particle sizes in the range of $250-500 \mu \mathrm{m}$. The active catalyst was tightly packed between two quartz wool plugs, with the active catalyst zone of length $2 \mathrm{~mm}$, in a bed length of $25 \mathrm{~mm}$. In this arrangement, the thin-zone TAP reactor configuration was approached. The inert quartz tube used to house the fixed bed, as adapted by van Veen and co-workers [23], was placed in the metallic body to suppress adsorption and further reaction on the walls as well as provide mechanical stability. Anhydrous DME (99.999\%) and argon (99.999\%) were obtained from CK special gases Ltd. Ultra-high purity water-free methanol (99.8\%) was purchased from Aldrich.

The experimental set up allowed for the formation of active $\mathrm{H}$-form of the zeolite catalyst by decomposition of the ammonium form under vacuum conditions. Probe molecules ( $5 \mathrm{vol} \%$ DME or $5 \mathrm{vol} \%$ methanol in Ar) were fed to the TAP 
system using continuous feeding valves. The concentrations of probe molecules were calibrated against signal intensity by passing streams of gas in argon over an inert quartz bed catalyst of similar dimensions. From the mass spectra data, sensitivity coefficients were obtained and further used to obtain the molar flow rates during TPD experiments. Argon was monitored at $\mathrm{m} / \mathrm{e}=40, \mathrm{CH}_{3} \mathrm{OH}$ at $\mathrm{m} / \mathrm{e}=31$, DME at $\mathrm{m} / \mathrm{e}=45, \mathrm{H}_{2} \mathrm{O}$ at $\mathrm{m} / \mathrm{e}=18, \mathrm{CO}$ at $\mathrm{m} / \mathrm{e}=28, \mathrm{CO}_{2}$ at $\mathrm{m} / \mathrm{e}=44$, $\mathrm{H}_{2}$ at $\mathrm{m} / \mathrm{e}=2, \mathrm{CH}_{4}$ at $\mathrm{m} / \mathrm{e}=16, \mathrm{C}_{2} \mathrm{H}_{4}$ at $\mathrm{m} / \mathrm{e}=27$, and $\mathrm{C}_{3} \mathrm{H}_{6}$ at m/e $=41$. Over ZSM-5 (36) and ZSM-5 (135) only DME or methanol was observed individually in the desorption profile. However, over ZSM-5 (25), following DME desorption, there was some release of methanol. Subsequent deconvolution allowed for the subtraction of minor fragments of other species from the main species.

\subsection{Characterization}

The zeolite samples were studied by X-ray diffraction (XRD) with a Bruker D5005 diffractometer using $\mathrm{Cu} \mathrm{K}_{\alpha}$ radiation equipped with standard Bragg-Brentano geometry and a diffracted beam graphite monochromator. The morphology was characterized using a Carl Zeiss sigma series Field Emission Scanning Electron Microscope (FE-SEM) at an accelerated voltage of $20 \mathrm{kV}$. The crystal size distribution was obtained from an image analysis software. Nitrogen physisorption studies were carried out on a Micromeritics 2020 unit. The samples were degassed by heating to $400{ }^{\circ} \mathrm{C}$ under vacuum $\left(10^{-6} \mathrm{mbar}\right)$ for $12 \mathrm{~h}$ prior to measurements.

\subsection{Acid Site Density Determination}

Zeolite catalyst samples were calcined in air $\left(50 \mathrm{~mL} \mathrm{~min}^{-1}\right)$ ex-situ at $450{ }^{\circ} \mathrm{C}$ for $2 \mathrm{~h}$. The catalyst powders were then pressed into self-supporting discs, and loaded into a custommade thermogravimetric infrared cell with a CI Precision MK2-M5 LM 2-01 microbalance and a Bruker Vertex 70 FTIR spectrometer. The catalyst discs were heated to $215^{\circ} \mathrm{C}$ in $\mathrm{N}_{2}\left(10 \mathrm{~mL} \min ^{-1}\right)$ for $2 \mathrm{~h}$ to dehydrate the sample before being cooled to an initial adsorption temperature of $100{ }^{\circ} \mathrm{C}$ where a spectrum was collected. Pyridine was then introduced to the samples by the flow of $\mathrm{N}_{2}$ gas over a schlenk flask containing pyridine. Sample temperature was then raised to $128^{\circ} \mathrm{C}$. Spectra and the total mass due to pyridine adsorption were recorded at both temperatures which then permits absorption coefficients for bands due to two independent modes of vibration for Lewis and Brønsted bound pyridine to be determined. The values of the absorption coefficients then permits the individual numbers of Brønsted and Lewis acid sites to be determined [24]. Although signal to noise ratio in some samples was lower than ideal, determination of molar absorption coefficients using the above methodology permitted a cross-check that these were consistent with published values [24] and thus a degree of confidence in the values obtained for the densities of the of Brønsted and Lewis acid sites was afforded.

\subsection{TPD Experiments}

Before the start of each TPD experimental series, the catalysts were pre-heated at $15{ }^{\circ} \mathrm{C} \mathrm{min}^{-1}$ under vacuum conditions up until $450{ }^{\circ} \mathrm{C}$ and held for $30 \mathrm{~min}$ before subsequently cooled down at $25{ }^{\circ} \mathrm{C} \mathrm{min}{ }^{-1}$ to room temperature. TPD experiments were carried out firstly by pre-adsorbing the pre-treated catalyst with a continuous flow of $5 \mathrm{vol} \%$ methanol or 5 vol\% DME in Ar until saturation. Thereafter, weakly adsorbed species were removed from the surface by argon flowing at ca. $10^{-7} \mathrm{~mol} \mathrm{~s}^{-1}$ giving a maximum velocity of $10^{-1} \mathrm{~m} \mathrm{~s}^{-1}$. Thereafter, the catalyst was subjected to a linear temperature ramp at three different heating rates of $\left(=5,15\right.$ or $\left.30^{\circ} \mathrm{C} \mathrm{min}{ }^{-1}\right)$ until a final set point of $450{ }^{\circ} \mathrm{C}$. The released gas was analysed using a quadrupole mass spectrometer (QMS) operating in a multiple ion detector (MID) mode. The low base pressure $\left(10^{-7} \mathrm{~Pa}\right)$ in the analysis chamber allowed for high detection sensitivity necessary for quantitative analysis. The effect of initial coverage of DME (or methanol) was studied separately on ZSM-5 (36) at a heating rate of $15{ }^{\circ} \mathrm{C} \mathrm{min}^{-1}$. The initial coverages were obtained by an integration of desorption profile.

\subsection{Steady State Experiments}

The ZSM-5 catalyst was calcined in a $20 \mathrm{~mL} \mathrm{~min}{ }^{-1}$ flow of $30 \mathrm{vol} \% \mathrm{O}_{2} / \mathrm{N}_{2}$ in a fixed bed reactor at $450{ }^{\circ} \mathrm{C}$ and held for $30 \mathrm{~min}$ before cooling down at $25^{\circ} \mathrm{C} \mathrm{min}^{-1}$ to $370{ }^{\circ} \mathrm{C}$. Afterwards, the catalyst was subjected to a flow of $1.3 \mathrm{vol} \%$ methanol in nitrogen at $10 \mathrm{~mL} \mathrm{~min}{ }^{-1}$ for $2 \mathrm{~h}$ to generate the hydrocarbon pool species in the zeolite micropores. The off-gas was analysed with an online gas chromatograph (Shimadzu GC-2010) equipped with an Equity-1 column $(90 \mathrm{~m} \times 0.53 \mathrm{~mm} \times 3.0 \mu \mathrm{m})$ and a flame ionization detector followed by a quadrupole mass spectrometer. The samples with the hydrocarbon species occluded in the zeolite pores will be referred to as "active samples" hereafter.

\subsection{Desorption Profile Model}

Two approaches were used to simulate TPD profiles: (i) the Redhead method [25] and (ii) the detailed elementary step model. The desorption profile was firstly deconvoluted and analysed using the Redhead method. Originally developed for the desorption of species over metal surfaces, the Redhead method gives a quick indication of the nature of the active sites as well as the maximum temperatures of desorption, number of binding sites and number of molecules 


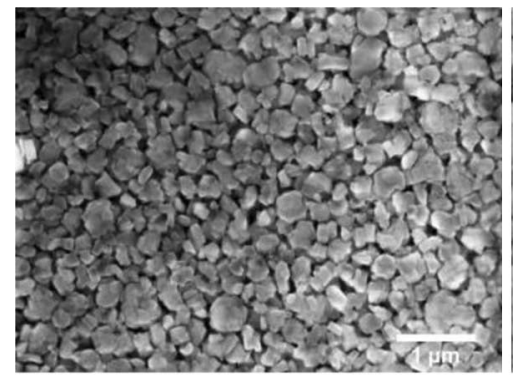

(a) ZSM-5 (25)

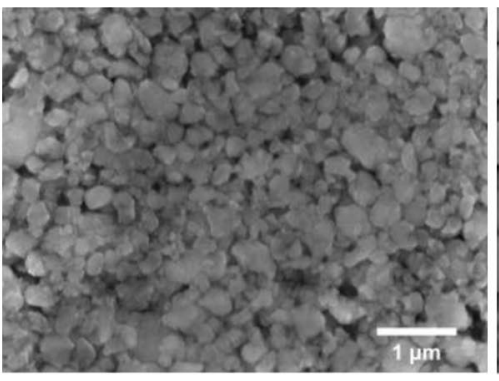

(b) ZSM-5 (36)

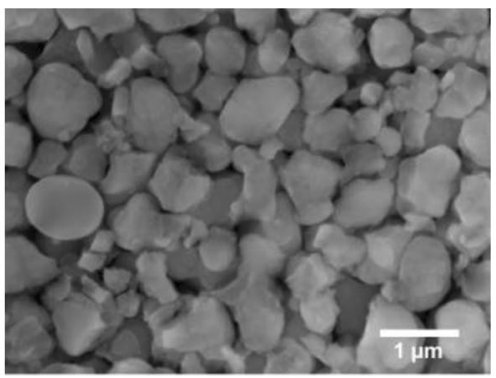

(c) ZSM-5 (135)

Fig. 1 FE-SEM of a ZSM-5 (25), b ZSM-5 (36) and c ZSM-5 (135) catalysts

Table 1 Physical properties and acidity of H-ZSM-5 catalysts

\begin{tabular}{|c|c|c|c|c|c|c|c|}
\hline Sample & $\begin{array}{l}\text { BET surface } \\
\text { area }\left(\mathrm{m}^{2} \mathrm{~g}^{-1}\right)\end{array}$ & $\begin{array}{l}\text { HK pore vol- } \\
\text { ume }\left(\mathrm{cm}^{3} \mathrm{~g}^{-1}\right)\end{array}$ & $\begin{array}{l}\text { Crystal size } \\
(\mathrm{SEM}, \mu \mathrm{m})\end{array}$ & $\begin{array}{l}\text { Nominal acid- } \\
\text { ity }\left(\mu \mathrm{mol} \mathrm{g}^{-1}\right)\end{array}$ & $\begin{array}{l}\text { Total acidity } \\
\left(\mu \mathrm{mol} \mathrm{g}{ }^{-1}\right)\end{array}$ & $\begin{array}{l}\text { Amount of Lewis } \\
\text { acid sites }\left(\mu \mathrm{mol} \mathrm{g} \mathrm{g}^{-1}\right)\end{array}$ & $\begin{array}{l}\text { Amount of Brønsted } \\
\text { acid sites }\left(\mu \mathrm{mol} \mathrm{g} \mathrm{g}^{-1}\right)\end{array}$ \\
\hline ZSM-5 (25) & 413 & 0.154 & $0.10 \pm 0.02$ & 610 & 496 & 140 & 356 \\
\hline ZSM-5 (36) & 410 & 0.147 & $0.33 \pm 0.05$ & 429 & 197 & 80 & 117 \\
\hline ZSM-5 (135) & 358 & 0.141 & $0.78 \pm 0.07$ & 116 & 108 & 30 & 78 \\
\hline
\end{tabular}

HK Horvath-Kawazoe micropore volume

${ }^{\text {a }}$ Total acidity based on pyridine adsorption at $100{ }^{\circ} \mathrm{C}$

adsorbed onto each binding site. However, there are a few limitations as discussed in Sect. 3.2.3.

To overcome these limitations, the detailed elementary step model was also used as described in Sect. 3.2.5 using data obtained from the Redhead method as initial guess values for estimation of desorption parameters. The model was implemented with a FORTRAN code and used to extract desorption parameters (site densities, frequency factors and activation energies) over the ZSM-5 catalysts. The code uses a PDASAC routine to solve the stiff, nonlinear initialboundary-value problem obtained from the desorption profiles [26]. A similar method has been used by Rebrov and co-workers [27, 28].

\section{Results}

\subsection{Characterization}

Catalytic active sites can be present inside the zeolite micropores, the pore mouth, and onto the external surface of the crystals [29]. FE-SEM images give in depth data into the crystal structure. Characteristic SEM images of three zeolite samples with $\mathrm{Si} / \mathrm{Al}$ ratio of 25, 36 and 135 are shown in Fig. 1. The mean crystal size data of those samples are listed in Table 1.

The XRD patterns of the three ZSM-5 samples and a reference ZSM-5 pattern are shown in Fig. 2. It can be seen

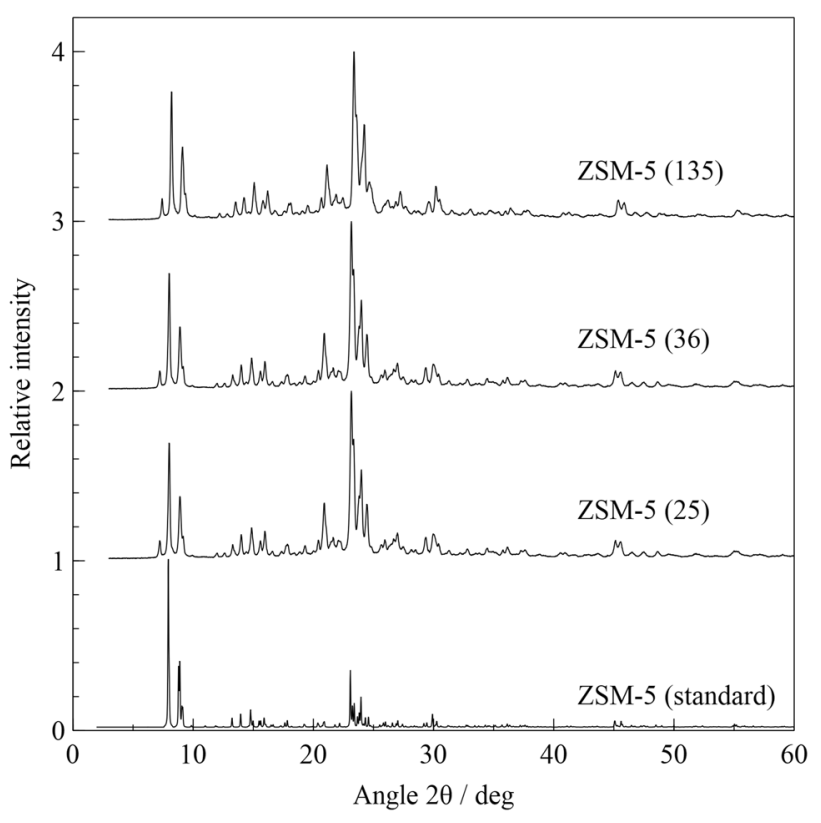

Fig. 2 XRD patterns of the ZSM-5 samples and a reference highly crystalline ZSM-5 sample (standard) obtained from the database of the International Zeolite Association [30]

that all three samples are highly crystalline zeolites with the MFI structure. The higher intensity of the XRD pattern of ZSM-5 (135) compared to the ZSM-5 (25) and ZSM-5 (36) shows its higher crystallinity. The lower intensities of 
ZSM-5 (25) and ZSM-5 (36) are probably due to their small crystal sizes which lead to a higher proportion of framework and structure defects. In Fig. 2, relative intensities have been plotted to show the similar zeolite characteristics.

ZSM-5 (25, 36 and 135) show a distribution of micropores and mesopores. The BET surface areas and the micropore volumes of the ZSM-5 samples are given in Table 1.

The IR spectra of pyridine adsorbed on the $\mathrm{H}$-form of ZSM-5 (25), ZSM-5 (36) and ZSM-5 (135) show features due to pyridinium ions formed via the protonation of pyridine on Brønsted acid sites as well as molecular pyridine on strong Lewis acid sites (Fig. 3). The most evident band distinguishing molecular pyridine on strong Lewis acid sites is at $1450 \mathrm{~cm}^{-1}$ similar to alumina and silica-alumina [31, 32] while pyridinium ions give rise to the characteristic band at $1545 \mathrm{~cm}^{-1}$ with both forms of adsorption contributing to the intensity at $1490 \mathrm{~cm}^{-1}$ [33]. In addition to this qualitative assessment, coupling to a gravimetric balance permitted the total acidity to be assessed (Table 1) along with the individual contributions due to adsorption on the different acid sites when coupling balance and FTIR data. Total acidity follows the trend ZSM-5 (25) > (36) > (135) which is consistent with the trend for nominal acidity. The major contribution to base adsorption in all cases was due to uptake by Brønsted acid sites (Table 1) with the relative percentages of this mode of adsorption being 72,59 and $72 \%$ for ZSM-5 (25), (36) and (135), respectively. At $128^{\circ} \mathrm{C}$, the

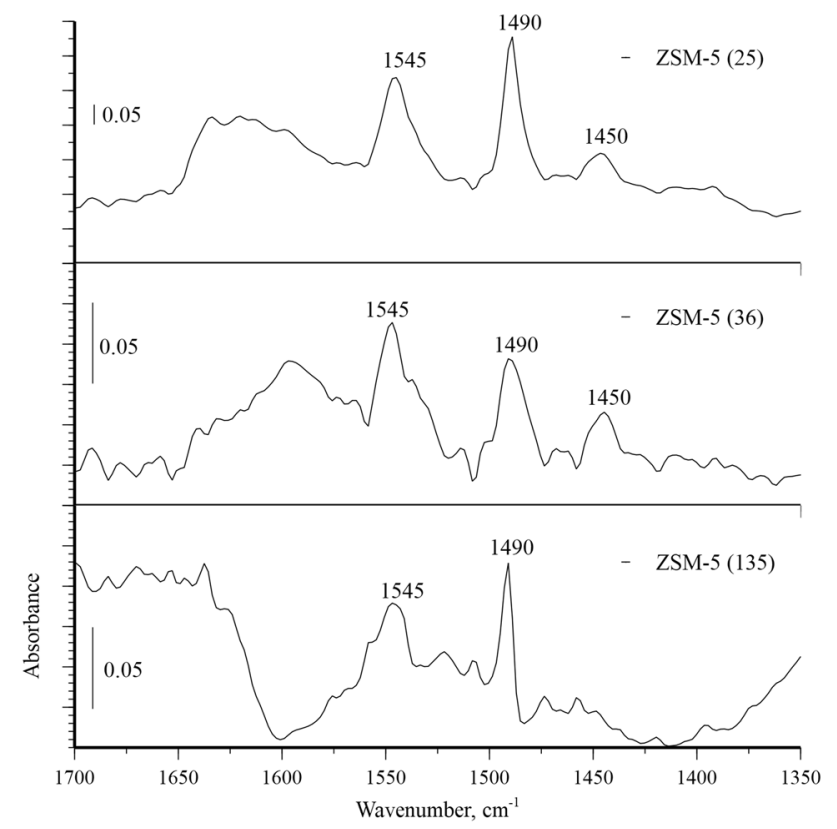

Fig. 3 FT-IR spectra of ZSM-5 (25), ZSM-5 (36) and ZSM-5 (135) zeolite samples (previously activated by outgassing at $450{ }^{\circ} \mathrm{C}$ ), and then exposed to pyridine vapour at $100{ }^{\circ} \mathrm{C}$ and subsequent outgassing at $128{ }^{\circ} \mathrm{C}$ relative percentages are 88, 77\% for ZSM-5 (25) and (36) respectively.

\subsection{Methanol and DME TPD}

\subsubsection{Desorption}

The rate of desorption, which describes the desorption profile in the absence of activated re-adsorption, is described by Eq. (1).

$r_{d e s}=-\frac{d \theta}{d t}=k_{d} \theta^{n}=\theta^{n} A_{d} \exp \left(-E_{d} / R T\right)$

where $\theta$ is the surface density of adsorbed molecules (mol $\left.\mathrm{m}^{-3}\right), n$ is the order of desorption, $T$ is the temperature (K), $A_{d}$ is the pre-exponential factor $\left(\mathrm{s}^{-1}\right), E_{d}$ is the activation energy for desorption $\left(\mathrm{J} \mathrm{mol}^{-1}\right)$. At a constant heating rate, $(\beta, \mathrm{K} \mathrm{min}-1)=d T / d t$, the rate of desorption can be rearranged as follows:

$r_{\text {des }}=-\frac{d \theta}{d T}=\frac{\theta^{n} A_{d}}{\beta} \exp \left(-E_{d} / R T\right)$

Desorption profiles of methanol to DME over the ZSM-5 (25) catalyst are compared in Fig. 4. Several features are observed. Firstly, the rate of desorption of methanol is higher than that of DME, demonstrating that a larger amount of methanol molecules occupies the sites and desorbs at any time. Secondly, the DME desorption profile shifts to the higher temperatures as compared to that of methanol. This suggests that DME adsorption is much stronger. Thirdly, there are several desorption sites as evidenced by the presence of shoulders in the desorption profiles. This is a common feature of all TPD profiles over fresh and activated ZSM-5 catalysts at full initial coverage.

\subsubsection{Effect of Variation of Initial Coverage}

The initial coverage of the pre-adsorbed oxygenates onto the fresh ZSM-5 (36) catalyst was varied by altering the adsorption duration. The initial coverage was obtained by integration of desorption curves and the total number of acid sites as determined from FTIR/microbalance data of pyridine adsorption at $128^{\circ} \mathrm{C}$. It was observed that oxygenates are adsorbed onto different acid sites in the order of decreasing strength, with highest energy sites filling up first. Their desorption occurred in the reverse order with the lowest energy sites being emptied first. The integration of Eq. 2 at maximum temperature leads to a temperature independence of the peak position on initial coverage for a first order desorption process and a temperature dependence for a second order desorption process $[34,35]$. Our results suggest that methanol desorption follows a first order kinetics (Fig. 5a) while 


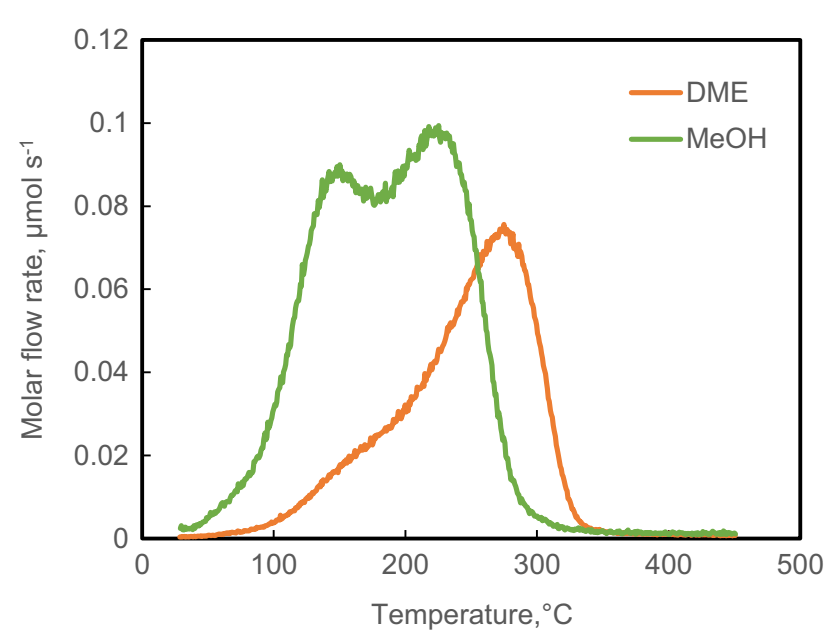

Fig. 4 Desorption profiles of methanol and DME over fresh ZSM-5 (25) at $15^{\circ} \mathrm{C} \min ^{-1}$

DME desorption follows a second order kinetics (Fig. 5b) as the position of the DME desorption peak decreases at higher initial coverages.

The discussion above does not consider the fact that the overall profile can be deconvoluted into different individual peaks and each desorption peak can have its own desorption kinetics. While the order of desorption kinetics may vary for each site, their contributions could still lead to the behaviour exhibited by the overall desorption profile. Also, it dismisses the effect of re-adsorption which results in peak broadening of the desorption profile. Under vacuum conditions in the TAP reactor, methanol has a maximum saturation coverage of 0.43 and DME has a maximum saturation coverage of 0.28 . Increasing the dosing pressure has been shown to raise the saturation coverage of adsorbents in similar TPD studies [36]. Finally, the lower temperature binding sites are only observed at high coverages.

\subsubsection{Effect of Heating Rate}

Redhead [25] proposed a method for desorption profile analysis based on the analysis of maximum temperatures. An assumption of the order of desorption must be made first. It is well established that the addition of acids to alcohols leads to the formation of a relatively stable oxonium salt which could decompose under suitable conditions [37, 38]. The same can be observed for DME. Here, the products are methanol and methoxy groups [39]. This behaviour supports dissociative (i.e. second order) adsorption. According to Redhead (25), second order desorption is characterized by a surface coverage which is half the initial surface coverage at maximum temperature. This is evidenced by fitting symmetrical Gaussian curves over the TPD profiles for each site. In this case, a plot of $\left(2 \ln T_{p, \text { max }}-\ln \beta\right) v s 1 / T_{p, \max }$
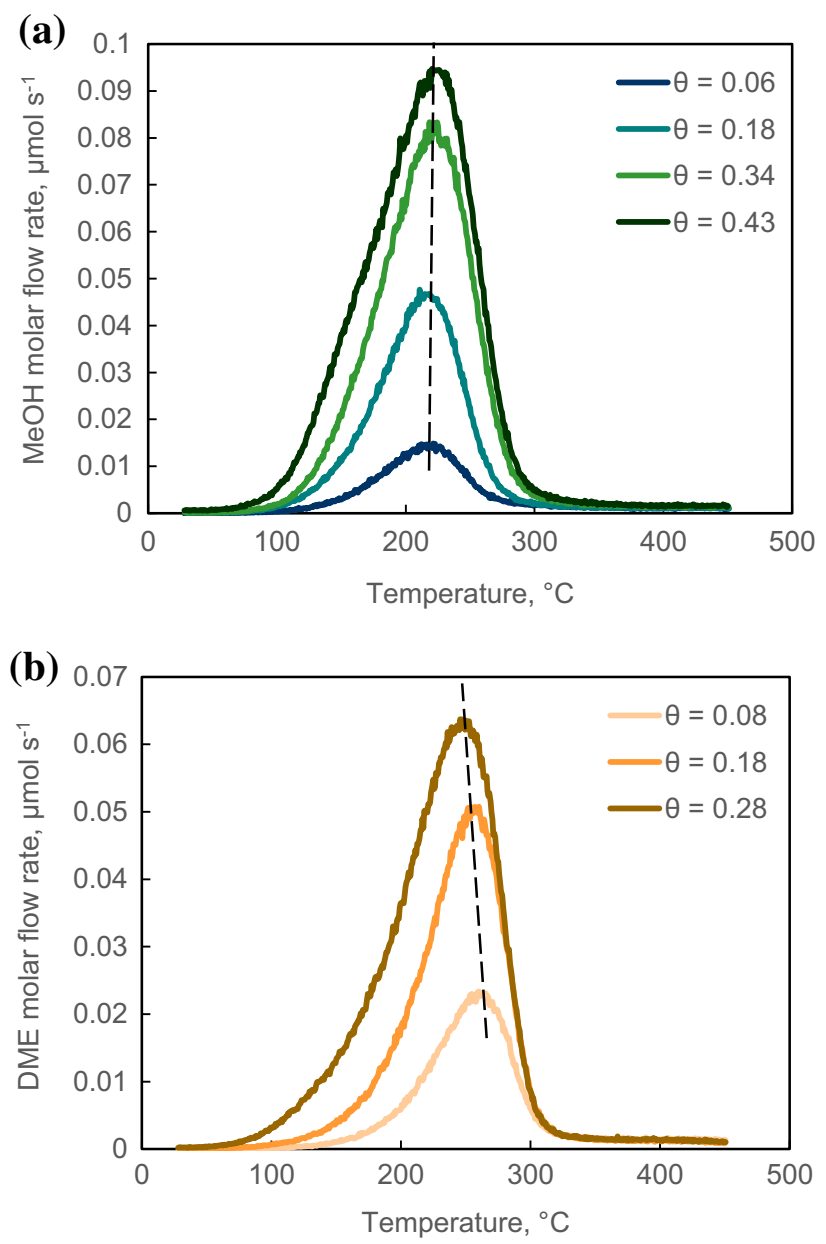

Fig. 5 The effect of initial coverage on a methanol and b DME desorption over fresh ZSM-5 (36) catalyst at a heating rate of $15{ }^{\circ} \mathrm{C}$ $\min ^{-1}$

gives the activation energies of desorption and the desorption rate constant in the absence of re-adsorption $\left(T_{p}\right.$, max is the temperature of maximum desorption at each site). In this method, across heating rates $\left(5,15\right.$ and $\left.30{ }^{\circ} \mathrm{C} \min ^{-1}\right)$, the width as well as ratio of the areas across site were kept constant for each desorbing specie. Starting with an approximation of second order desorption where methanol dissociates on the active sites, three desorption sites were observed over ZSM-5 (25) and ZSM-5 (36) and two desorption sites over ZSM-5 (135) for both methanol and DME. The three desorption sites_-sites 1,2 and 3-are here referred to as low temperature (LT), medium temperature (MT) and high temperature (HT) sites. A representative example of a DME desorption profile is presented in Fig. 6.

In the absence of re-adsorption, Fig. 7 gives the desorption activation energy obtained with the Redhead method. A common trend can be observed over all ZSM-5 catalysts studied: the activation energy of desorption of DME is 
greater than that of methanol over fresh ZSM-5 catalysts. For example, an activation energy of DME desorption of $42.0 \mathrm{~kJ} \mathrm{~mol}^{-1}$ is higher compared to $31.6 \mathrm{~kJ} \mathrm{~mol}^{-1}$ for methanol over ZSM-5 (36). Over activated ZSM-5 (36) and ZSM-5 (135) catalysts, the activation energy of desorption of DME is greater than that of methanol. However, over activated ZSM-5 (25), the activation energy of desorption of DME is less than that of methanol. For completion, other parameters (desorption frequency factors) for fresh and activated catalysts are given in $\mathrm{S} 1$ and $\mathrm{S} 2$ of the supplementary information respectively.

\subsubsection{Amount of Species Adsorbed Onto Each Site}

Further analysis of the desorption profiles was carried out over the zeolite samples to obtain the amount of specie

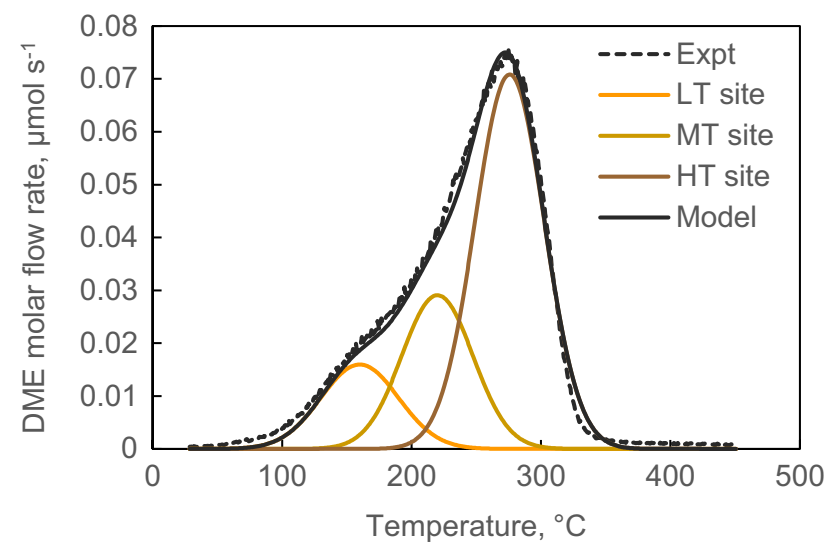

Fig. 6 Desorption profile of DME from a fresh ZSM-5 (25) catalyst at a heating rate of $15{ }^{\circ} \mathrm{C} \mathrm{min}{ }^{-1}$ with its fitting to 3 sites using the Redhead method accessible to each site. The areas under each Gaussian curve give the amount of species adsorbed onto each site. Analysis was carried out on desorption profiles obtained at $15{ }^{\circ} \mathrm{C}$ $\mathrm{min}^{-1}$ as the ratio of each site was kept constant at all heating rates during data analysis. Thus, the results obtained are tenable at $5{ }^{\circ} \mathrm{C} \mathrm{min}{ }^{-1}$ and at $30{ }^{\circ} \mathrm{C} \mathrm{min}{ }^{-1}$. The number of molecules per active sites was derived using nominal acidity (active sites/gram) obtained from $\mathrm{Si} / \mathrm{Al}$ ratios. The total amounts of methanol and DME adsorbed on each site of the fresh ZSM- 5 catalysts are given in Tables 2 and 3 .

Table 2 shows that more methanol molecules were adsorbed on each adsorbed site than DME. A clustering effect has been mentioned previously to account for multiple molecules on the adsorption site [40].

Tables 2 and 3 show that a lower amount of DME species is adsorbed compared to methanol. Given the limited amount of deactivation (Fig. 8) on the ZSM-5 catalysts after $2 \mathrm{~h}$ on stream, the number of molecules adsorbed per active site is indicative of the occupancy of non-deactivating species, possibly the adsorbed hydrocarbon pool, present in the porous network of the zeolite. It can be readily observed that the amount of DME species adsorbed stays roughly constant over fresh and activated ZSM-5 catalysts. A similar behaviour exists for methanol adsorption over ZSM-5 (25) and ZSM-5 (36). However, a notable difference in adsorption amount is observed between fresh and activated ZSM-5 (135) catalysts.

\subsubsection{Effect of Re-adsorption}

A detailed elementary step model that accounts for readsorption and desorption was used to describe the desorption profiles. The following stoichiometry was used:

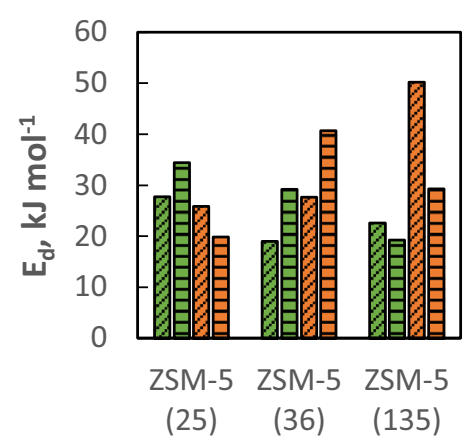

(a) LT site

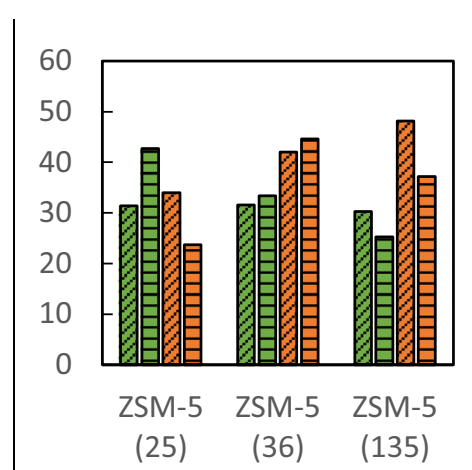

(b) MT site

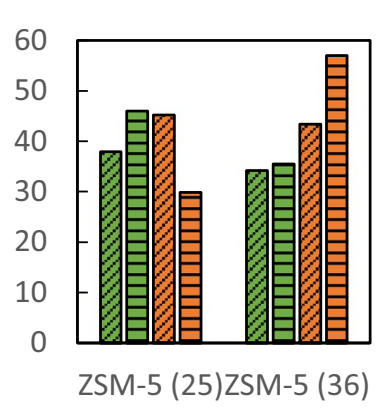
Q Methanol over fresh ZSM-5
日 Methanol over activated ZSM-5
口DME over fresh ZSM-5
日DME over activated ZSM-5

Fig. 7 A comparison of activation energy of desorption of methanol and DME over fresh and activated ZSM-5 catalysts over low (LT), medium (MT) and high (HT) temperature sites 
Table 2 Adsorption stoichiometry over different adsorption sites onto fresh ZSM-5 catalysts

\begin{tabular}{|c|c|c|c|c|c|c|}
\hline \multirow[t]{2}{*}{ Sample } & \multicolumn{3}{|l|}{$\mathrm{MEOH}$} & \multicolumn{3}{|l|}{ DME } \\
\hline & $\begin{array}{l}\text { Molecules/active } \\
\text { site-LT site }\end{array}$ & $\begin{array}{l}\text { Molecules/active } \\
\text { site-MT site }\end{array}$ & $\begin{array}{l}\text { Molecules/active } \\
\text { site-HT site }\end{array}$ & $\begin{array}{l}\text { Molecules/active } \\
\text { site-LT site }\end{array}$ & $\begin{array}{l}\text { Molecules/active } \\
\text { site-MT site }\end{array}$ & $\begin{array}{l}\text { Molecules/ } \\
\text { active site- } \\
\text { HT site }\end{array}$ \\
\hline ZSM-5 (25) & 2.7 & 2.5 & 3.6 & 0.8 & 1.3 & 3.1 \\
\hline ZSM-5 (36) & 3.4 & 2.8 & 6.1 & 0.9 & 1.3 & 2.5 \\
\hline ZSM-5 (135) & 2.9 & 6.9 & 0 & 2.3 & 4.1 & 0 \\
\hline
\end{tabular}

Table 3 Adsorption stoichiometry over different adsorption sites onto active ZSM-5 catalysts

\begin{tabular}{|c|c|c|c|c|c|c|}
\hline \multirow[t]{2}{*}{ Sample } & \multicolumn{3}{|l|}{ MEOH } & \multicolumn{3}{|l|}{ DME } \\
\hline & $\begin{array}{l}\text { Molecules/active } \\
\text { site_LT site }\end{array}$ & $\begin{array}{l}\text { Molecules/active } \\
\text { site-MT site }\end{array}$ & $\begin{array}{l}\text { Molecules/active } \\
\text { site-HT site }\end{array}$ & $\begin{array}{l}\text { Molecules/active } \\
\text { site_LT site }\end{array}$ & $\begin{array}{l}\text { Molecules/active } \\
\text { site-MT site }\end{array}$ & $\begin{array}{l}\text { Molecules/ } \\
\text { active site- } \\
\text { HT site }\end{array}$ \\
\hline ZSM-5 (25) & 2.8 & 2.3 & 3.9 & 0.6 & 1.8 & 2.3 \\
\hline ZSM-5 (36) & 2.1 & 2.1 & 4.1 & 0.6 & 1.5 & 3.3 \\
\hline ZSM-5 (135) & 7.9 & 11.8 & 0 & 2.3 & 3.3 & 0 \\
\hline
\end{tabular}

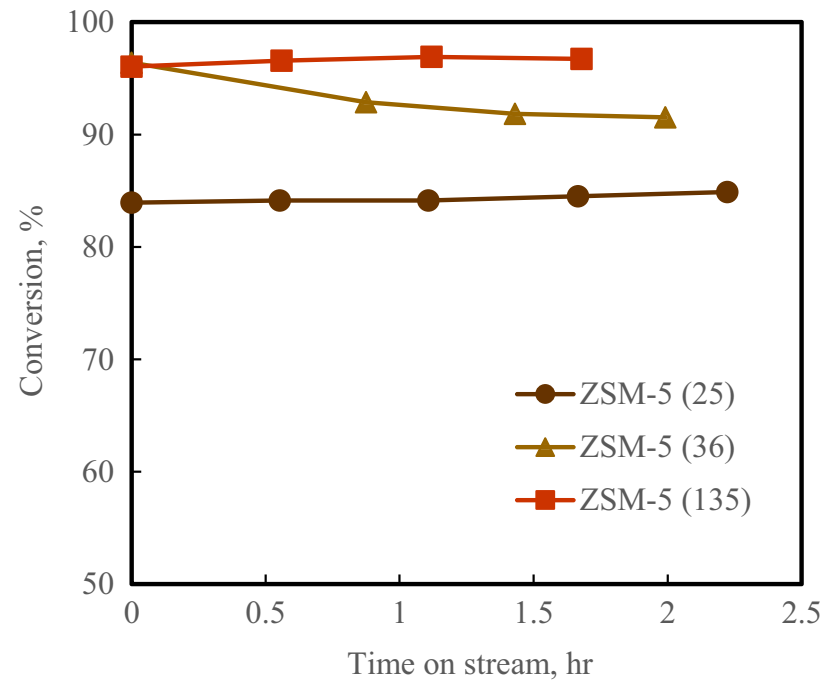

Fig. 8 Pre-activation of ZSM-5 samples at $370{ }^{\circ} \mathrm{C}, 2 \mathrm{~h}$ time on stream (TOS), $10 \mathrm{~mL} \mathrm{~min}^{-1}$ of $1.3 \mathrm{vol} \%$ methanol in nitrogen. Pressure $=1 \mathrm{bar}$

$$
\begin{aligned}
& \text { Site 1: } \mathrm{CH}_{3} \mathrm{OH}+* \quad \mathrm{CH}_{3} \mathrm{OCH}_{3}+* \rightleftharpoons \mathrm{CH}_{3} \mathrm{OCH}_{3} * \\
& \rightleftharpoons \mathrm{CH}_{3} \mathrm{OH} * \\
& \text { Site 2: } \mathrm{CH}_{3} \mathrm{OH}+2 * \quad \mathrm{CH}_{3} \mathrm{OCH}_{3}+2 * \rightleftharpoons \mathrm{CH}_{3} *+\mathrm{CH}_{3} \mathrm{O} * \\
& \rightleftharpoons \mathrm{CH}_{3} *+\mathrm{OH} * \\
& \text { Site 3: } \mathrm{CH}_{3} \mathrm{OH}+2 * \quad \mathrm{CH}_{3} \mathrm{OCH}_{3}+2 * \rightleftharpoons \mathrm{CH}_{3} *+\mathrm{CH}_{3} \mathrm{O} * \\
& \rightleftharpoons \mathrm{CH}_{3} *+\mathrm{OH} *
\end{aligned}
$$

where $*$ denotes an adsorption site
Using initial estimates from the Redhead method (25), the model allowed for three desorption sites on ZSM-5 (25) and ZSM-5 (36) and two desorption sites on ZSM-5 (135). The desorption profiles on three sites over ZSM-5 (25) and ZSM-5 (36) were modelled using a plug flow reactor with coupled convection, adsorption and desorption steps (see S3 in supplementary information). The model was adjusted appropriately for ZSM-5 (135) where two desorption sites were observed. A comparison of 5 desorption models (Table 4) to experimental data was made. The comparison of these models was based on a sum of squares error (SSE):

$\sum_{i}^{n}\left(Y_{\text {expt }}-Y_{\text {model }}\right)^{2} \rightarrow \min$

where $\mathrm{Y}_{\text {expt }}$ is the experimental desorption profile and $\mathrm{Y}_{\text {model }}$ is the simulated desorption profile. The best description (minimum SSE) allowed for a very good match between dissociative adsorption on MT and HT sites and molecular adsorption on the LT sites.

As shown in Fig. 7, the Redhead model gives different values of activation energies of desorption for fresh and activated ZSM-5 catalysts. With the detailed elementary step model, such specificity between fresh and active catalyst was hardly seen albeit in the difference in site densities. However, major differences arise between methanol and DME desorption. A sample desorption profile is given at a heating 
Table 4 A comparison of different models for methanol desorption over ZSM-5 (36) using sum of square error

\begin{tabular}{lllll}
\hline Model & LT $($ site 1$)$ & MT $($ site 2) & HT (site 3) & SSE \\
\hline A & Molecular adsorption & Molecular adsorption & Molecular adsorption & 3.019 \\
B & Dissociative adsorption & Dissociative adsorption & Dissociative adsorption & 2.575 \\
C & Molecular adsorption & Dissociative adsorption & Dissociative adsorption & 0.016 \\
D & Molecular adsorption & Molecular adsorption & Dissociative adsorption & 3.018 \\
& Single site & & & \\
E & Molecular adsorption & & & 2.485 \\
\hline
\end{tabular}

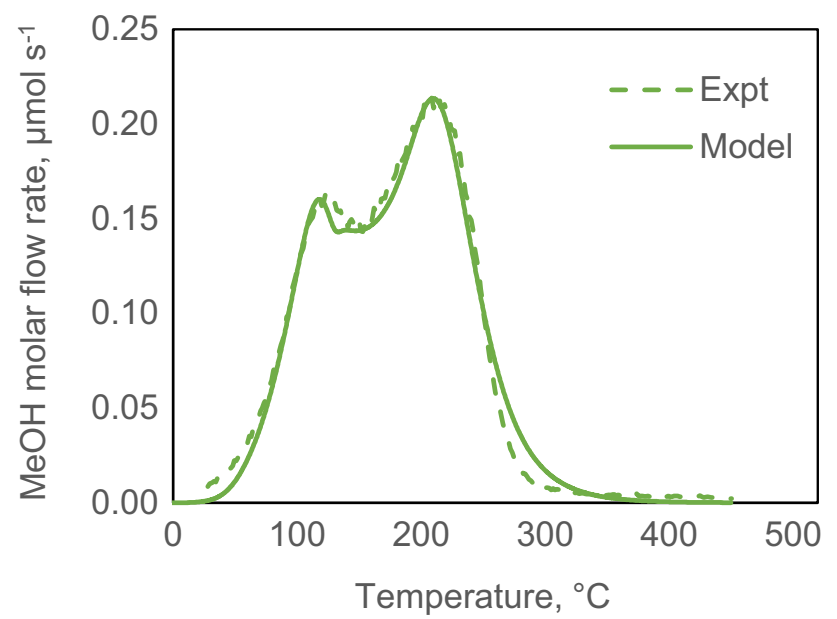

Fig. 9 Methanol desorption profile over fresh ZSM-5 (36) at $30{ }^{\circ} \mathrm{C}$ $\min ^{-1}$

rate of $30{ }^{\circ} \mathrm{C} \mathrm{min}^{-1}$ (Fig. 9). Activation energies of desorption obtained are presented in Fig. 10. For completion, other parameters (adsorption and desorption frequency factors) for all catalysts studied are given in S4 of the supplementary information.

As can be observed above, the activation energies of desorption are higher over ZSM-5 catalysts when re-adsorption is considered. In all cases, as observed with the Redhead method, the activation energies of desorption of DME over the various ZSM- 5 catalysts are greater than that of methanol.

Given that the plug flow reactor model with coupled convection, adsorption and desorption steps involving molecular adsorption on LT sites and dissociative adsorption on MT and HT sites gives the best match to experimental data, the sensitivity coefficients of the rate constant of each elementary step were calculated. To assess the sensitivity coefficient, each rate constant was multiplied by perturbation factors of 5 or 0.2 while other rate constants were kept constant. The relative changes in desorption profiles were obtained with or without the perturbation factor. Subsequently, the sensitivity coefficient was obtained as presented in Eq. 4 [41]:

$K_{s}=\frac{\ln \left(Y_{P} / Y_{O}\right)}{\ln (F)}$ where $Y_{p}$ and $Y_{o}$ are the rates with and without perturbation and $\mathrm{F}$ is the perturbation factor. Figure 11 shows the sensitivity coefficients of each parameter.

\section{Discussion}

\subsection{Limiting Factors}

The TAP reactor developed by Gleaves and co-workers [42] is conventionally used for pulse response experiments due to its sub-millisecond time resolution. Here, it has been exploited for TPD experiments as its operation under vacuum is necessary to reduce the influence of re-adsorption.

Two methods have been used to quantify desorption: the Redhead model and the detailed elementary step model, both based on a fundamental Polanyi-Wigner desorption kinetics. The Redhead model only considers the kinetics of desorption, while the detailed elementary step model, based on species balance, also considers possible re-adsorption effects and fluid flow through the packed bed.

Mass transport effects accompanying desorption have been discussed in depth in the literature [43-45]. As the pressures used were much lower than 1 mbar, external mass transfer to the particle is negligible due to low gas densities which allow for the absence of a stagnant film around the particle in the TAP reactor. They are suppressed due to negligible intramolecular collisions under vacuum conditions [23]. Local temperature spikes are insignificant due to the very dilute oxygenate mixtures and the presence of fewer molecules in comparison with the thermal mass of the bed. In the absence of reaction, the thin-zone configuration of the TAP reactor allows for decoupling of diffusion from desorption with or without re-adsorption and eliminates the concentration gradients along the bed [46]. In the TPD profiles obtained, intra-particle diffusion does not limit the desorption/re-adsorption process according to the criteria given in Refs [43, 45, 47]. See S5 in supplementary information.

The TAP reactor has high detection capabilities due to its low detection limit and offers for an unperturbed shape of the desorption profiles caused by a direct placement of the measuring probe and mass spectrometer into the detection chamber. It is well known that the desorption profile 


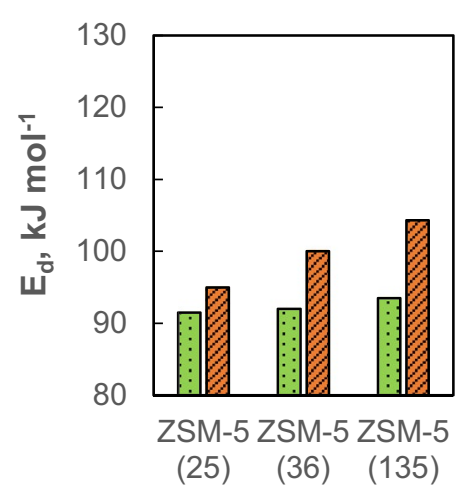

(a) LT site

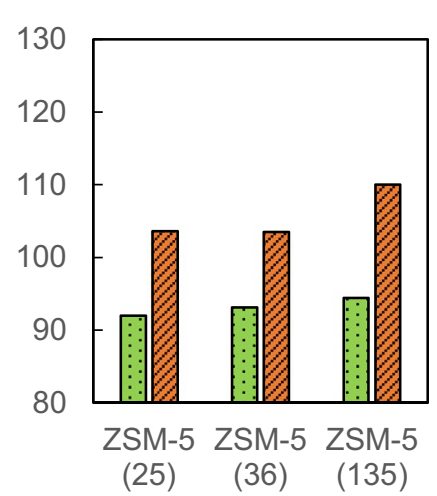

(b) MT site

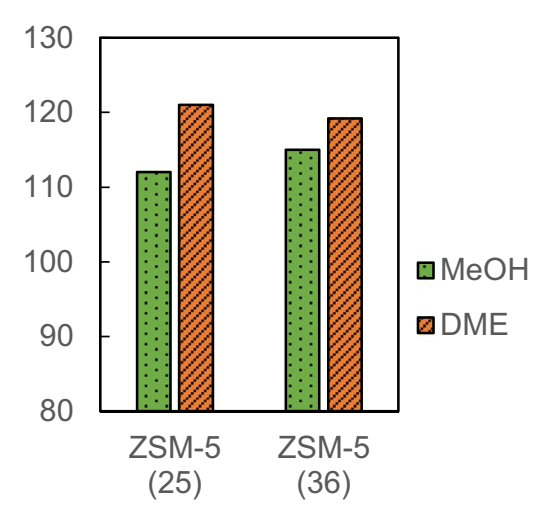

(c) HT site

Fig. 10 Comparison of the activation energy of desorption of methanol and DME over ZSM-5 catalysts derived using the detailed elementary step model

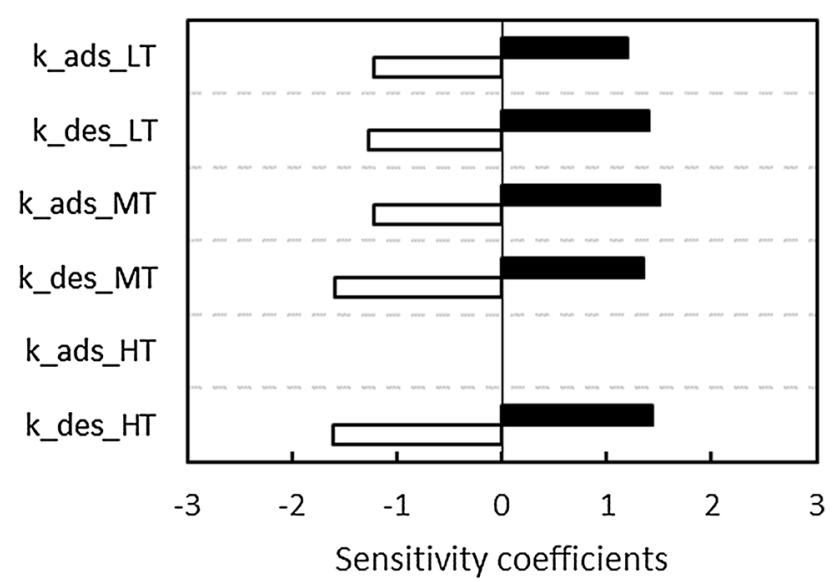

Fig. 11 Sensitivity coefficients for the desorption rates over fresh ZSM-5 (36) at a heating rate of $30{ }^{\circ} \mathrm{C} \mathrm{min}^{-1}$. $\mathrm{k} \_$ads_LT is the rate constant for adsorption over the low temperature site, $\mathrm{k}$ _des_LT is the rate constant for desorption over the low temperature site

for strongly adsorbing molecules such as methanol can be significantly altered by the adsorption phenomena in the conventional mass spectrometer equipment which use an inlet capillary tube [48]. The removal of extra-particle mass transfer and decrease in the contribution of re-adsorption phenomena under vacuum conditions in the TAP reactor shows its immense benefit.

The conventional TAP method of time evolution of short pulses was originally initiated to be used to decouple adsorption and desorption of oxygenates (methanol, DME) over ZSM-5 catalyst following the methodology of Nijhuis and co-workers [49]. However, the lack of an outlet response of methanol following an inlet short pulse subjected our experimental methods to non-conventional methods in TAP of obtaining adsorption and desorption parameters under convective flow (see S6 in supplementary information). S6 shows full uptake of $\mathrm{CH}_{3} \mathrm{OH}$ regardless of temperature during pulse experiments and partial uptake of DME with an increasing response with temperature.

A comparison of experimental data and the detailed elementary step model leads to the observation of intrinsic activation energies of desorption. The model considers convection, adsorption and desorption parameters. This means adsorption and desorption occur at a certain location in the reactor. However, this is not the case in zeolites as adsorption and desorption occur in the pore and the released substance can only move towards the free gas space once it leaves the pore.

\subsection{Comparing Redhead Method to the Detailed Elementary Step Model}

Over the MT and HT sites, both the Redhead method and the detailed elementary step model allow for dissociative adsorption (second order desorption). Over the LT sites, while the Redhead method allowed for dissociative desorption, molecular desorption was indicative on the LT sites with the detailed elementary step model (Fig. 8). This disagreement between both methods was resolved by conducting TPD experiments at different initial coverages over the ZSM-5 (36) catalyst.

As mentioned previously, experiments conducted at different initial coverages showed that molecules fill up the sites in order of decreasing energies and desorb in order of increasing energies. At very high coverages, when low energy sites fill up, the temperatures at which maximum desorption occurs stay constant with the coverage over the LT 
site. Moreover, alternative models on the LT site assuming second order desorption gave a poor match between experiment and model. This provided further confidence in the detailed elementary step model showing that desorption is first order on the LT sites and second order on MT and HT sites. In the detailed elementary step model, re-adsorption leads to broadening on the LT and MT sites. This broadening effect gave an overlap between desorption temperatures in the LT and MT sites of ZSM-5 catalyst during methanol and DME desorption allowing for their direct comparison. In the TAP reactor, it has been shown that such re-adsorption can hardly be neglected over porous catalysts [42]. The higher activation energies of desorption obtained using the detailed elementary step model is due to re-adsorption effects which the Redhead method failed to account for.

\subsection{Comparing Desorption of Methanol to DME}

Methanol readily desorbs from the catalyst before DME does. The higher activation energy of desorption can be rationalised through proton-transfer chemisorption occurring through localized oxonium ion/framework anion pairs (Scheme 1). The binding energies of these oxonium ions are related to gas phase proton affinities of the adsorbing species [50]. The adsorption of methanol leads to the formation of a methoxonium $\left(\mathrm{CH}_{3} \mathrm{OH}_{2}{ }^{+}\right)$intermediate on Brønsted acid sites. On the other hand, the adsorption of DME leads to the formation of a dimethyloxonium ion $\left(\mathrm{DMO}^{+}\right)$intermediate [39]. The higher activation energies of desorption of DME compared to methanol over ZSM-5 catalysts suggests that DME has a higher proton affinity than methanol over Brønsted acid sites. Here, further dehydration of the oxonium ion intermediates formed to surface methoxy groups when heated in the TPD experiment occurs with equal propensity due to equal stability of the methoxy group formation with DME or methanol adsorption. Also, the probability for DME protonation is about 2 times higher than methanol suggesting higher tendencies towards larger activation energies of desorption for DME [51].

Higher values of activation energies of desorption of DME than methanol are generally in accordance with previous studies [40, 52-55] but in contrast to values obtained by Pope [56] through calorimetric methods (Table 5).

Both models show that a higher number of methanol molecules is adsorbed per active site compared to DME. Clusters of adsorbed methanol molecules have been proposed in the cages of zeolite catalysts $[40,55,57,58]$. Blaszkowski and van Santen [59] observed the end-on configuration where the hydroxyl groups of the methanol are directed towards the basic oxygen of the zeolite as a favourable geometry for methanol adsorption using density functional theory (DFT) calculations.

In summary, more methanol clusters are adsorbed on the zeolite catalyst than DME, although it takes lower temperatures to desorb them from the catalyst surface.

\subsection{Effect of Si/AI Ratio on the Desorption Kinetics in ZSM-5 Catalysts}

With the Redhead method, over fresh catalysts, DME has a higher activation energy of desorption than methanol. After catalyst activation during MTH conversion, DME still maintains a higher activation energy of desorption over ZSM-5 (36) and ZSM-5 (135). However, on the ZSM-5 (25) catalyst, DME has a lower activation energy of desorption compared to methanol. Firstly, it is important to state that the data obtained from ZSM-5 (25) should be treated cautiously as during TPD experiments of methanol, minor amounts of other species were desorbed suggesting a possible interaction between species.

The high acid site density of ZSM-5 (25) leads to a different product distribution (Fig. 12) as compared to ZSM-5 (36) and ZSM-5 (135) catalysts. The product distribution is representative of the well-established hydrocarbon pool
Scheme 1 Oxygenate dehydration over H-ZSM-5 catalysts

\begin{tabular}{ll}
\hline $\mathrm{CH}_{3} \mathrm{OH}+\mathrm{HZ} \rightleftharpoons \mathrm{CH}_{3} \mathrm{OH}_{2}^{+}+\mathrm{Z}^{-}$ & $\mathrm{CH}_{3} \mathrm{OCH}_{3}+\mathrm{HZ} \rightleftharpoons\left(\mathrm{CH}_{3}\right)_{2} \mathrm{OH}^{+}+\mathrm{Z}^{-}$ \\
$\mathrm{CH}_{3} \mathrm{OH}_{2}^{+}+\mathrm{Z}^{-} \rightleftharpoons \mathrm{CH}_{3}^{+}+\mathrm{H}_{2} \mathrm{O}$ & $\left(\mathrm{CH}_{3}\right)_{2} \mathrm{OH}^{+} \rightleftharpoons \mathrm{CH}_{3}^{+}+\mathrm{CH}_{3} \mathrm{OH}$
\end{tabular}

Table 5 Heats of desorption of species from ZSM-5 catalysts obtained from literature

\begin{tabular}{|c|c|c|c|c|c|c|}
\hline Sample & $\mathrm{Si} / \mathrm{Al}$ ratio & $\begin{array}{l}\text { Molecules/ } \\
\text { unit cell }\end{array}$ & Molecules/active site & $\mathrm{E}_{\mathrm{d}}\left(\mathrm{kJ} \mathrm{mol}^{-1}\right)$ & Method & Source \\
\hline \multirow[t]{2}{*}{ Methanol } & 36 & $1-2.5$ & $0.39-0.97$ & 74-107 & Calorimetric & (56) \\
\hline & & $2.5-16$ & $0.97-6.18$ & $47-74$ & & \\
\hline \multirow[t]{2}{*}{ Methanol } & 15 & $0-6$ & $0-1$ & $65-85$ & TPD & (53) \\
\hline & & $6-15$ & $1-2.5$ & $50-65$ & & \\
\hline \multirow[t]{2}{*}{ DME } & 36 & $1-2.5$ & $0.39-0.97$ & $20-94$ & Calorimetric & (56) \\
\hline & & $2.5-10$ & $0.97-3.86$ & 20 & & \\
\hline
\end{tabular}



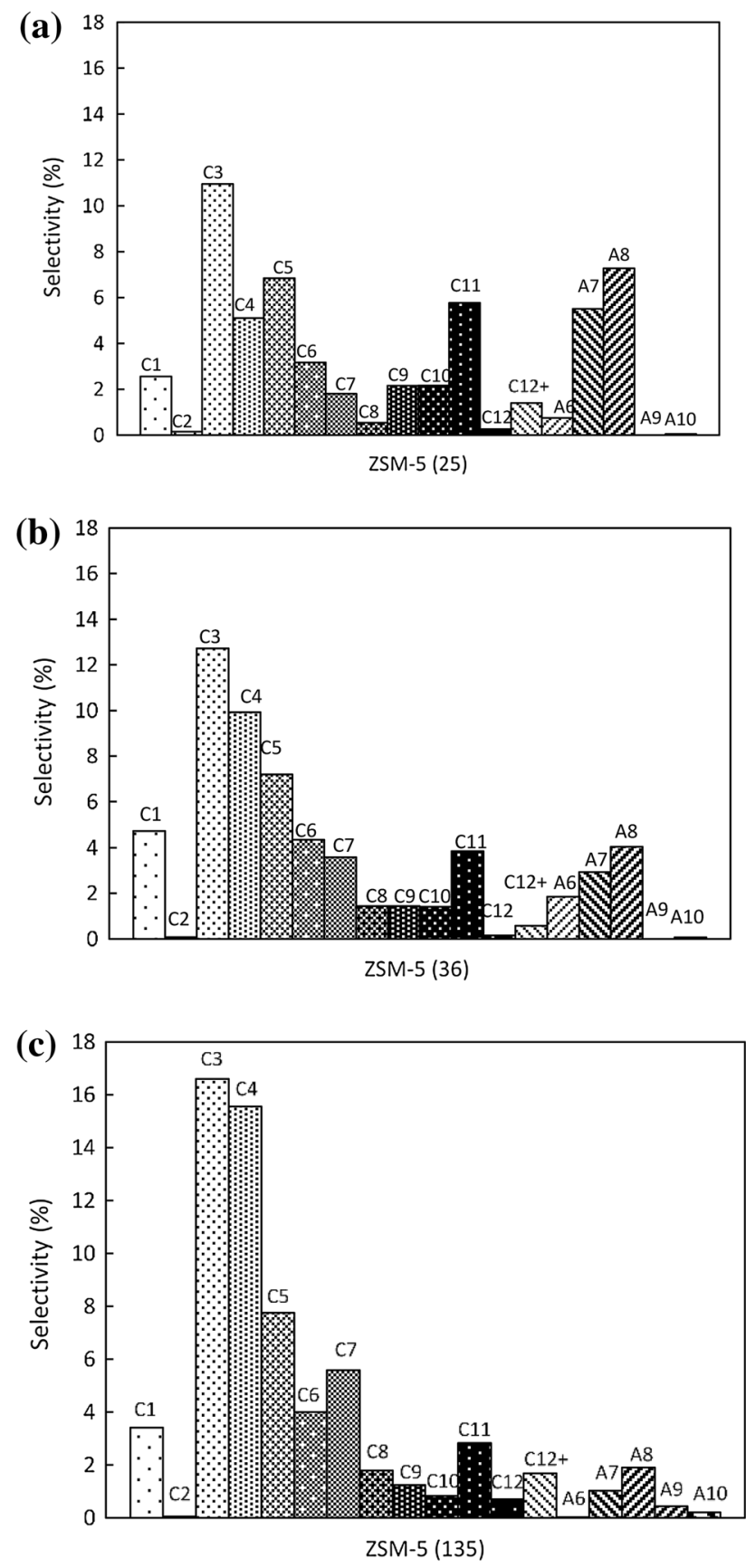

Fig. 12 Hydrocarbon pool distribution over a ZSM-5 (25), b ZSM-5 (36) and c ZSM-5 (135) catalysts at $370{ }^{\circ} \mathrm{C}, 2 \mathrm{~h}$ TOS, $10 \mathrm{~mL} / \mathrm{min}$ of $1.3 \mathrm{vol} \%$ methanol in nitrogen. Pressure $=1$ bar. A6 $=$ Benzene, $\mathrm{A} 7=$ Toluene, $\mathrm{A} 8=$ Xylene, $\mathrm{A} 9=$ Trimethylbenzene, $\mathrm{A} 10=$ Tetramethylbenzene

mechanism which is propagated to various proportions due to dissimilar acid densities of the various ZSM-5 catalysts. As shown in Fig. 12, ZSM-5 (25) has a lower selectivity of lower olefins and a higher selectivity of aromatics showing a prevalence of the aromatic cycle after $2 \mathrm{~h}$ time on stream (TOS). The occupancy of sites with prevalent species from the aromatic cycle over ZSM-5 (25) would lead to a larger constraint on the mobility of DME than methanol. Site blockage due to a dominant aromatic cycle on ZSM-5 (25) means that larger molecules such as DME are easily removed from the zeolite in comparison to methanol. The occupancy of sites with prevalent olefin species on ZSM-5 (36) and (135) leads to a lower constraint on the mobility of DME giving the expected behaviour as observed in Fig. 7. These effects of site occupancy are pronounced when adspecies move on the surface of the catalyst. When re-adsorption is accounted for as with the plug flow model with coupled convection, adsorption and desorption steps, these effects are largely removed.

\subsection{Nature of Binding Sites}

The desorption behaviour of oxygenates and the zeolite's pore architecture should be considered in understanding the nature of the binding sites. Two desorption sites were observed with ZSM-5 (135) and three desorption sites over ZSM-5 (25) and (36). A combination of the detailed elementary step model and experimental data showed that molecular adsorption occurs on the LT site while dissociative adsorption occurs on the MT and HT sites. Furthermore, re-adsorption occurs on the LT and MT sites only (S4 in supplementary information). The pore architecture shows higher space constraints in the pore channels $(0.53 \mathrm{~nm} \times 0.56 \mathrm{~nm}$ and $0.51 \mathrm{~nm} \times 0.55 \mathrm{~nm})$ than at the pore intersections $(0.9 \mathrm{~nm})$.

The plug flow reactor model accounts for differences between the desorption profiles of methanol and DME due to any associated re-adsorption and convective effects. Methanol binds weakly to sites in comparison to DME as it has lower activation energy of desorption and hence lower adsorption enthalpy. However, re-adsorption is much faster with methanol (see S4 in supplementary information). This means that methanol can move in the pore system without much restriction, but it re-binds very easily such that the recurrent adsorption-desorption process finally becomes limiting to the motion of the molecule. The higher recurrent interaction (re-adsorption) of methanol with the active sites give rise to lower desorption energies compared to DME.

The presence of re-adsorption over the LT and MT sites suggests a local equilibrium with the gas phase at these sites. Since the LT site is first order, observed desorption preexponential factors lower than $10^{13} \mathrm{~s}^{-1}$ suggests that the activated complex, just above the binding site, has a lower degree of freedom compared to its adsorbed state (34). The limited degree of freedom of the transition state in comparison to the adsorbed state is probably due to the clustering effect of oxygenates at each binding state which further hinders free movement. Dissociation which occurs in the zeolite pores allows for a higher partial molar entropy of 
the adsorbed oxygenate compared to the gas phase [60]. As mentioned previously, gases desorb from sites in order of increasing energies. As gases move from the HT sites to the LT sites, the surface concentration starts to increase leading to increasing probability of re-adsorption along the dimensions of the ZSM-5 zeolite.

Consideration of the adsorption stoichiometry (Table 2) shows that the MT and HT sites over ZSM-5 (25) and ZSM-5 (36) merge to give a MT site on ZSM-5 (135). In fact, the addition of the number of molecules/active site on MT and HT sites on ZSM-5 (25) and (36) gives the molecules/active site on MT sites on ZSM-5(135). This nullifies the conception that sites disappear over highly siliceous zeolites. TAP reactor data at low coverages show that over ZSM-5 (25), sites are relatively populated with active sites distributed within the zeolite. On increasing the $\mathrm{Si} / \mathrm{Al}$ ratio, merging of the sites occurs, leading to isolated sites preferentially located on the straight channels of the ZSM-5 catalyst [61].

In addition, there is high convergence between the percentage of sites from MT and HT (69, 72 and $70 \%$ for ZSM-5 (25), (36) and (135) respectively) to Brønsted acid site density at $100{ }^{\circ} \mathrm{C}$ (See Table 1 and S7 in supplementary information). Thus, this simplified microkinetic model along with pyridine FTIR data would suggest the MT and HT sites to be of a Brønsted acid nature and the LT site to be of a Lewis acid nature. The agreement between the nature of the sites and their desorption behaviour solidifies this relationship. Accessibility to binding sites and site density using pyridine FT-IR data is different from oxygenate adsorption. This is due to the different molecular kinetic diameters, different temperatures of adsorption and different basicity. Clearly, the clustering effect on the ZSM-5 catalyst gives a far higher number of molecules adsorbed (as obtained from the detailed elementary step model) compared to the density of active sites obtained through pyridine FTIR.

\section{Conclusions}

The desorption of methanol and dimethyl ether (DME) has been studied over ZSM-5 catalysts with different $\mathrm{Si} / \mathrm{Al}$ ratios. Three desorption sites were observed over ZSM-5 catalysts, while two of them cannot be distinguished in the sample with a $\mathrm{Si} / \mathrm{Al}$ ratio of 135 and were observed as a single peak. Based on the shape of desorption peaks, it can be concluded that molecular adsorption takes place on the low temperature binding sites while dissociative adsorption occurs on the medium and high temperature binding sites. A comparison of pyridine FTIR data and microkinetic modelling suggests the medium and high temperatures sites are of Brønsted acid nature due to their dissociative nature. The low temperature sites correspond to a Lewis acid nature due to their molecular adsorption properties. For both oxygenates, re-adsorption occurs on the low and medium temperature binding sites but does not occur on the high temperature binding sites. Overall, methanol desorbs easily in comparison to DME, showing that adsorbed DME is the primary oxygenate and key methylating agent in surface reactions during $\mathrm{MTH}$ conversion.

Acknowledgements Financial support from the Petroleum Technology Development Fund of Nigeria (PTDF/ED/PHD/OO/766/15) and from the European Commission in the scope of the 7th Framework program BIOGO project (Grant Number: 604296) https://www.biogo. $\mathrm{eu} /$ is acknowledged.

\section{Compliance with Ethical Standards}

Conflict of interest The authors declare no conflict of interest.

Open Access This article is distributed under the terms of the Creative Commons Attribution 4.0 International License (http://creativecommons.org/licenses/by/4.0/), which permits unrestricted use, distribution, and reproduction in any medium, provided you give appropriate credit to the original author(s) and the source, provide a link to the Creative Commons license, and indicate if changes were made.

\section{References}

1. Chang CD, Silvestri AJ (1977) The conversion of methanol and other O-compounds to hydrocarbons over zeolite catalysts. J Catal 47(2):249-259

2. Weitkamp J (2000) Zeolites and catalysis. Solid State Ionics 131(1-2):175-188

3. Babu GP, Hegde SG, Kulkarni SB, Ratnasamy P (1983) Active centres over HZSM5 zeolites. J Catal 81(2):471-477

4. Svelle S, Kolboe S, Swang O, Olsbye U (2005) Methylation of alkenes and methylbenzenes by dimethyl ether or methanol on acidic zeolites. J Phys Chem B 109(26):12874-12878

5. Haase F, Sauer J (2000) Ab initio molecular dynamics simulation of methanol interacting with acidic zeolites of different framework structure. Microporous Mesoporous Mater 35-36:379-385

6. Štich I, Gale JD, Terakura K, Payne MC (1999) Role of the zeolitic environment in catalytic activation of methanol. J Am Chem Soc 121(14):3292-3302

7. Hytha M, Štich I, Gale JD, Terakura K, Payne MC (2001) Thermodynamics of catalytic formation of dimethyl ether from methanol in acidic zeolites. Chem Eur J 7(12):2521-2527

8. Greatbanks SP, Hillier IH, Burton NA, Sherwood P (1996) Adsorption of water and methanol on zeolite Brønsted acid sites: an ab initio, embedded cluster study including electron correlation. J Chem Phys 105(9):3770-3776

9. O'Malley AJ, Logsdail AJ, Sokol AA, Catlow CRA (2016) Modelling metal centres, acid sites and reaction mechanisms in microporous catalysts. Faraday Discuss 188(0):235-255

10. Blaszkowski SR, Van Santen RA (1996) The mechanism of dimethyl ether formation from methanol catalyzed by zeolitic protons. J Am Chem Soc 118(21):5152-5153

11. Blaszkowski SR, Van Santen RA (1997) Theoretical study of C-C bond formation in the methanol-to- gasoline process. J Am Chem Soc 119(21):5020-5027

12. Blaszkowski SR, Van Santen RA (1997) Theoretical study of the mechanism of surface methoxy and dimethyl ether formation 
from methanol catalyzed by zeolitic protons. J Phys Chem B 101(13):2292-2305

13. Wang W, Seiler M, Hunger M (2001) Role of surface methoxy species in the conversion of methanol to dimethyl ether on acidic zeolites investigated by in situ stopped-flow MAS NMR spectroscopy. J Phys Chem B 105(50):12553-12558

14. Bjørgen M, Joensen F, Lillerud KP, Olsbye U, Svelle S (2009) The mechanisms of ethene and propene formation from methanol over high silica H-ZSM-5 and H-beta. Catal Today 142(1-2):90-97

15. Bjørgen M, Svelle S, Joensen F, Nerlov J, Kolboe S, Bonino F, Palumbo L, Bordiga S, Olsbye U (2007) Conversion of methanol to hydrocarbons over zeolite H-ZSM-5: On the origin of the olefinic species. J Catal 249(2):195-207

16. Liang J, Li H, Zhao S, Guo W, Wang R, Ying M (1990) Characteristics and performance of SAPO-34 catalyst for methanol-to-olefin conversion. Appl Catal 64:31-40

17. Vora BV, Marker TL, Barger PT, Nilsen HR, Kvisle S, Fuglerud T. In: de Pontes M (1997) Economic route for natural gas conversion to ethylene and propylene In: Espinoza RL, Nicolaides CP, Scholtz JH, Scurrell MS (eds) Studies in surface science and catalysis, vol 107. Elsevier, Amsterdam, pp 87-98

18. Koempel H, Liebner W (2007) Lurgi.'s methanol to propylene (MTP®) report on a successful commercialisation. Stud Surf Sci Catal 167:261-267

19. Chang CD, Lang WH, Smith RL (1979) The conversion of methanol and other O-compounds to hydrocarbons over zeolite catalysts.II. Pressure effects. J Catal 56(2):169-173

20. Ilias S, Bhan A (2013) Mechanism of the catalytic conversion of methanol to hydrocarbons. ACS Catal 3:18-31

21. Chang CD (1980) A kinetic model for methanol conversion to hydrocarbons. Chem Eng Sci 35(3):619-622

22. Chen NY, Reagan WJ (1979) Evidence of autocatalysis in methanol to hydrocarbon reactions over zeolite catalysts. J Catal 59(1):123-129

23. Van Veen AC, Zanthoff HW, Hinrichsen O, Muhler M (2001) Fixed-bed microreactor for transient kinetic experiments with strongly adsorbing gases under high vacuum conditions. J Vacuum Sci Technol Part A 19(2):651-655

24. McCue AJ, Mutch GA, McNab AI, Campbell S, Anderson JA (2016) Quantitative determination of surface species and adsorption sites using Infrared spectroscopy. Catal Today 259:19-26

25. Redhead PA (1962) Thermal desorption of gases. Vacuum 12(4):203-211

26. Caracotsios M, Stewart WE (1995) Sensitivity analysis of initialboundary-value problems with mixed pdes and algebraic equations. Comput Chem Eng 19(9):1019-1030

27. Rebrov EV, Simakov AV, Sazonova NN, Rogov VA, Barannik GB (1998) Propane and oxygen action on NOx adspecies on lowexchanged Cu-ZSM-5. Catal Lett 51(3-4):27-40

28. Rebrov EV, Simakov AV, Sazonova NN, Stoyanov ES (1999) Dinitrogen formation over low-exchanged Cu-ZSM-5 in the selective reduction of NO by propane. Catal Lett 58(2-3):107-118

29. Busca G (1999) The surface acidity of solid oxides and its characterization by IR spectroscopic methods.An attempt at systematization. Phys Chem Chem Phys 1(5):723-736

30. Baerlocher C, McCusker LB Database of zeolite structures. http:// www.iza-structure.org/databases/. Accessed 1 Aug 2017

31. Phung TK, Lagazzo A, Rivero Crespo M, Sánchez Escribano V, Busca G (2014) A study of commercial transition aluminas and of their catalytic activity in the dehydration of ethanol. J Catal 311:102-113

32. Kassab E, Castellà-Ventura M (2005) Theoretical study of pyridine and 4,4'-bipyridine adsorption on the Lewis acid sites of alumina surfaces based on ab initio and density functional cluster calculations. J Phys Chem B 109(28):13716-13728
33. Castellà-Ventura M, Akacem Y, Kassab E (2008) Vibrational analysis of pyridine adsorption on the brønsted acid sites of zeolites based on density functional cluster calculations. J Phys Chem C 112(48):19045-19054

34. Madix RJ (1979) The kinetics of elementary reactions on crystal surfaces. AIP conference, the physics of surfaces: aspects of the kinetics and dynamics of surface reactions. La Jolla Institute, San Diego

35. Boudart M, Djega-Mariadassou G (1984) Kinetics of heterogeneous catalytic reactions. Princeton University Press, Princeton

36. Genger T, Hinrichsen O, Muhler M (1999) The temperatureprogrammed desorption of hydrogen from copper surfaces. Catal Lett 59(2-4):137-141

37. Pines H (1981) Acid-catalyzed reactions the chemistry of catalytic hydrocarbon conversions. Academic Press, Cambridge

38. Gates BC (1991) Catalytic chemistry. Wiley, New York

39. Park TY, Froment GF (2001) Kinetic modeling of the methanol to olefins process. 1. Model formulation. Ind Eng Chem Res 40(20):4172-4186

40. Mirth G, Lercher JA, Anderson MW, Klinowski J (1990) Adsorption complexes of methanol on zeolite ZSM-5. J Chem Soc Faraday Trans 86(17):3039-3044

41. Caracotsios M, Stewart WE (1985) Sensitivity analysis of initial value problems with mixed odes and algebraic equations. Comput Chem Eng 9(4):359-365

42. Gleaves JT, Ebner JR, Kuechler TC (1988) Temporal analysis of products (TAP) - a unique catalyst evaluation system with submillisecond time resolution. Catal Rev 30(1):49-116

43. Demmin RA, Gorte RJ (1984) Design parameters for temperatureprogrammed desorption from a packed bed. J Catal 90(1):32-39

44. Tronconi E, Forzatti P (1986) Modelling and experimental verification of TPD from porous catalysts. Chem Eng Sci 41(10):2541-2545

45. Rieck JS, Bell AT (1984) Influence of adsorption and mass transfer effects on temperature-programmed desorption from porous catalysts. J Catal 85(1):143-153

46. Shekhtman SO, Yablonsky GS, Chen S, Gleaves JT (1999) Thin-zone TAP-reactor-theory and application. Chem Eng Sci 54(20):4371-4378

47. Gorte RJ (1982) Design parameters for temperature programmed desorption from porous catalysts. J Catal 75(1):164-174

48. Kanervo JM, Kouva S, Kanervo KJ, Kolvenbach R, Jentys A, Lercher JA (2015) Prerequisites for kinetic modeling of TPD data of porous catalysts-exemplified by toluene/H-ZSM-5 system. Chem Eng Sci 137:807-815

49. Nijhuis TA, Van Den Broeke LJP, Linders MJG, Van De Graaf JM, Kapteijn F, Makkee M, Moulijn JA (1999) Measurement and modeling of the transient adsorption, desorption and diffusion processes in microporous materials. Chem Eng Sci 54(20):4423-4436

50. Aronson MT, Gorte RJ, Farneth WE (1986) The influence of oxonium ion and carbenium ion stabilities on the Alcohol/H-ZSM-5 interaction. J Catal 98(2):434-443

51. Martinez-Espin JS, De Wispelaere K, Westgård Erichsen M, Svelle S, Janssens TVW, Van Speybroeck V, Beato P, Olsbye U (2017) Benzene co-reaction with methanol and dimethyl ether over zeolite and zeotype catalysts: evidence of parallel reaction paths to toluene and diphenylmethane. J Catal 349:136-148

52. Zecchina A, Bordiga S, Spoto G, Scarano D, Spanò G, Geobaldo F (1996) IR spectroscopy of neutral and ionic hydrogen-bonded complexes formed upon interaction of $\mathrm{CH} 3 \mathrm{OH}, \mathrm{C} 2 \mathrm{H} 5 \mathrm{OH}$, (CH3)2O, (C2H5)2O and C4H8O with H-Y, H-ZSM-5 and $\mathrm{H}$-mordenite: comparison with analogous adducts formed on the H-Nafion superacidic membrane. J Chem Soc Faraday Trans 92(23):4863-4875

53. Hunger B, Matysik S, Heuchel M, Einicke WD (1997) Adsorption of methanol on ZSM-5 zeolites. Langmuir 13(23):6249-6254 
54. Fujino T, Kashitani M, Kondo JN, Domen K, Hirose C, Ishida M, Goto F, Wakabayashi F (1996) T-IR and quantum chemical studies of the interaction between dimethyl ether and IZSM-5 zeolite. J Phys Chem 100(28):11649-11653

55. Lee CC, Gorte RJ, Farneth WE (1997) Calorimetric study of alcohol and nitrile adsorption complexes in H-ZSM-5. J Phys Chem B 101(19):3811-3817

56. Pope CG (1993) Adsorption of methanol and related molecules on zeolite H-ZSM-5 and silicalite. J Chem Soc Faraday Trans 89(7):1139-1141

57. Shah R, Gale JD, Payne MC (1996) Methanol adsorption in zeolites-a first-principles study. J Phys Chem 100(28):11688-11697
58. Sinclair PE, Catlow CRA (1996) Computational studies of the reaction of methanol at aluminosilicate Brønsted acid sites. J Chem Soc Faraday Trans 92(12):2099-2105

59. Blaszkowski SR, Van Santen RA (1995) Density functional theory calculations of the activation of methanol by a Brønsted zeolitic proton. J Phys Chem 99(30):11728-11738

60. Riekert L (1970) Sorption, diffusion, and catalytic reaction in zeolites. Adv Catal 21:281-322

61. Titiloye JO, Parker SC, Stone FS, Catlow CRA (1991) Simulation studies of the structure and energetics of sorbed molecules in highsilica zeolites. 1. Hydrocarbons. J Phys Chem 95(10):4038-4044

\section{Affiliations}

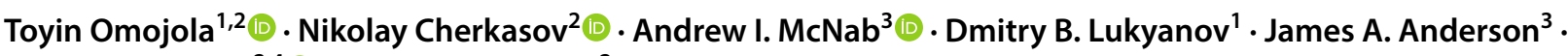 Evgeny V. Rebrov ${ }^{2,4}$ (i) André C. van Veen ${ }^{2}$}

$\triangle$ André C. van Veen

andre.vanveen@warwick.ac.uk

1 Department of Chemical Engineering, University of Bath, Claverton Down, Bath BA2 7AY, UK

2 School of Engineering, University of Warwick, Library Road, Coventry CV4 7AL, UK
3 Chemical and Materials Engineering Group, School of Engineering, University of Aberdeen, Aberdeen AB24 3UE, UK

4 Department of Biotechnology and Chemistry, Tver State Technical University, A. Nikitina st., 22, Tver, Russia 170026 